\title{
Nos êxitos e nos fracassos humanos: a mística da terra na cosmovisão de Pierre Teilhard de Chardin
}

\author{
Aparecida Maria de Vasconcelos
}

\section{Resumo}

A mística vem sendo apontada por diversos teólogos como um dos caminhos para a humanização, provocação para o diálogo inter-religioso e também como um dos pontos mais vigorosos quanto ao futuro do cristianismo. O objetivo desse artigo é expor as principais intuições da mística de Teilhard de Chardin que pode ser considerada como a mística da Terra. Nossa reflexão seguirá três momentos. Primeiro, a estrutura básica do pensamento do autor. Segundo, sua reflexão mística concernente às atividades e passividades. Finalmente, algumas reações que brotaram do estudo para o atual contexto da cultura plurireligiosa.

Palavras-chave: Mística, Terra, Atividades, Passividades.

\begin{abstract}
The mystic has been mentioned by several theologists as one for the ways of humanization. It also triggers the dialogue among religions as well as being one of the most vigorous points regarding the future of Christianity. The
\end{abstract}


aim of this article is to expose the main intuitions of Teilhard Chardin's mystic which can be considered as the mystic of the Earth. Our reflection will focus on three stages. First, the basic structure of the author's thought. Second, his mystic reflection concerning activities and passivities. Finally, some reactions generated by his work to the present context of multi religious culture.

Keywords: Mystic, Earth, Activities, Passivities.

\section{Introdução}

A mística vem sendo apontada por diversos teólogos como um dos caminhos para a humanização, provocação para o diálogo inter-religioso e também um dos pontos mais vigorosos capaz de salvaguardar o cristianismo. Realidade da ordem da gratuidade, ela é um olhar para além do tempo, que segue os movimentos do Espírito. É sensibilidade que capta o âmago da realidade passada, presente e que há de vir, descortinando a verdade que liberta e "faz novas todas coisas". Na tradição cristã, nosso objeto de estudo, a mística ou misticismo ganha diversos tons... Riquezas verdadeiramente incontestáveis, expressões pluriformes!

A mística da Terra, na visão do geopaleontólogo jesuíta Pierre Teilhard de Chardin, é a expressão do seu caminho espiritual inaciano marcado pelo cristocentrismo, fundida à sua apaixonada visão do universo em evolução, convergido para o ponto ideal no tempo futuro, o Ponto Ômega. Nessa dinâmica ele convida os homens a lançarem-se em cheio no real, valorizando e assumindo as melhores forças da terra, trabalhando sem desfalecimento para construírem um mundo onde triunfe a esperança e o gosto de viver. E mais: a integrarem os sofrimentos e os fracassos numa perspectiva sobrenatural.

Começar pela genealogia do jesuíta francês pode parecer anódino. No entanto, esta escolha nada tem de banal, pois a sua vida fascinante determina, em muitos aspectos, a singularidade do seu pensamento. Assim, como ponto de partida dessa exposição, interessa-nos esboçar o contexto no qual nosso autor viveu e, de modo sintético, as linhas estruturantes do seu pensamento. Em seguida, abordaremos o tema em questão, que encontra-se desenvolvido em duas partes: a divinização das atividades e a divinização das passividades. Por fim, apresentaremos alguns prolongamentos e provocações que o estudo suscitou. 


\section{Ciência, Filosofia e Teologia como biografia}

Marie Joseph Pierre Teilhard de Chardin nasceu em $1^{\circ}$ de maio de 1881 , em Sarcenat - Auvergne, França, e morreu em 10 de abril de 1955 em Nova York, festa da Páscoa. Estudou filosofia em Jersey (Inglaterra), de 1908 a 1912 fez teologia em Hastings (Inglaterra). Esta formação intelectual é interrompida durante os dois anos de magistério no Cairo (1906-1908), onde lecionou ciências físicas. Esta foi a sua primeira incursão no Oriente que ocupará uma tão grande parte de sua vida.

Por ocasião da Primeira Guerra Mundial (1914-1918), serviu como cabo maqueiro (padioleiro) e capelão oficial do $8^{\circ}$ regimento de infantaria tunisino. Esse período foi ocasião de experiências decisivas, por sua vez intelectuais e místicas, que determinaram a evolução de sua reflexão ulterior. De 1919 a 1923 realizou seus estudos de paleontologia e geologia em Paris. Teilhard foi enviado para a China para continuar as suas pesquisas em geologia e paleontologia. Aí, participou da descoberta do Sinanthropus ${ }^{1}$ e fez viagens pela Birmânia, Índia, Java. De 1923 a 1945, a China tornou a sua residência permanente. Este exílio, entrecortado por cinco breves estadias na França, vai revelar-se de uma extraordinária fecundidade científica, teológica e espiritual.

$\mathrm{Na}$ concepção de um universo aberto e evolutivo, o movimento geral do universo desdobra-se em três grandes fases: a cosmogênese (conjunto de fenômenos pelos quais o cosmos se formou); a biogênese (conjunto de fenômenos que presidem o surgimento da vida); a noogênese (surgimento da reflexão consciente no homem). Nesse desdobramento, a originalidade: a $4^{\mathrm{a}}$ fase - a cristogênese (momento final e pleromático da evolução). Aqui, precisamente, formula-se para Teilhard o problema do futuro: a evolução termina no homem? Como ela poderá se prolongar? Ele então postula a tese do Ponto Ômega ${ }^{2}$.

\footnotetext{
${ }^{1}$ Teilhard, nas escavações da caverna de Choukoutien (a $40 \mathrm{Km}$ de Pequim), participou na descoberta do Sinanthropus, que ele identificou como um pré-humano. Trata-se efetivamente de um dos primeiros homo erectus da Ásia oriental que aí viveu cerca de um milhão de anos.

${ }^{2}$ Para Teilhard Ômega é um modo de designar pela última letra do alfabeto grego o pólo atrativo do Universo. No seu pensamento a palavra recebe três sentidos. Num primeiro, o Ômega é de caráter puramente científico. Significa o ponto de maturação da convergência universal. A ciência não estabelece com exatidão as características desse ponto, porque ele se projeta num futuro "fora do tempo e do espaço". Num segundo, o Ômega ganha uma perspectiva filosófica. É uma meta a alcançar convertendo-se em centro de atração motora e convergente que, desde o interior, estimula os centros energéticos do universo. Finalmente, o Ômega é de natureza teológica. É o Deus transcendente, criador, Encarnado e final. Sob o aspecto da encarnação ele assume as feições do Cristo ressuscitado em que se realiza a conjunção do centro cósmico universal e do centro transcendente.
} 
Esta diz respeito ao ponto de convergência na interpretação da evolução do mundo rumo ao futuro, no qual se concentram todas as linhas de força do cosmos e todas as criações e os valores do espírito humano. $\mathrm{O}$ anúncio joanino no qual se afirma que Cristo é o Princípio e o Fim, o Alfa e o Ômega (cf. Ap $1,8)$ inspira nosso cientista místico. Segundo ele, a humanidade, pelas razões de uma ciência e pelos apelos de uma Fé, caminha para a união e, finalmente, para a consumação "in Christo Jesu".

Essa visão é uma síntese audaciosa entre mundo, ser humano e Deus. Essa síntese demonstra a dupla paixão do jesuíta francês, a paixão do Absoluto e da Terra, cuja expressão espiritual consistiu, para ele, no inaciano "buscar a Deus em todas as coisas" e na ardente devoção ao Coração de Jesus, até consumar-se numa mística de união ao Cristo cósmico, alimentada no ensinamento paulino das Cartas do Cativeiro $^{3}$. A perspectiva de uma antropologia ligada à estrutura de um universo predestinado a aperfeiçoar-se em Cristo abre para o cristão a possibilidade de uma mística da Terra, que se realiza por uma espiritualidade de encarnação. Esta linha é trabalhada, por excelência, na obra O Meio Divino ${ }^{4}$. Neste pequeno livro ele nos mostra como cristificar o meio em que vivemos e a transcender a própria temporalidade. $\mathrm{O}$ foco da mística teilhardiana mostra como Deus nos espera nos acontecimentos que nos fazem crescer, mas também diminuir preenchendo nossa vida de sua presença.

\section{A mística da terra}

Há autores que denominam o misticismo teilhardiano como mística da terra $^{5}$. Concordamos e sustentamos com tal identificação. De fato, o jesuíta francês propôs um itinerário espiritual que abarca o cotidiano, sob uma dupla vertente de ação e de reação, de iniciativa e de dependência, ou como ele mesmo disse, de atividades e de passividades.

\footnotetext{
${ }^{3}$ Cf. VAZ, H. C. de L. “O Itinerário inaciano de Teilhard de Chardin”, Revista de Espiritualidade Inaciana 48 (2002) pp. 95-103. Aqui p. 98.

${ }^{4}$ Teilhard estabelece o conceito de Meio Divino como um campo-duração (espaço-tempo) energético e evolutivo, divino enquanto emanado de um foco que o centra, anima e orienta em sua totalidade. Cf. TEILHARD DE CHARDIN, P., Le milieu divin: essai de vie interieure. Seuil, Paris, 1957. (Tradução: O Meio Divino. Ensaio de vida interior. Cultrix, São Paulo, 1981. Doravante utilizaremos a tradução portuguesa. Aqui pp. 48, nota n. 70).

${ }^{5}$ Cf. MARTINAZZO, F., "Visão Cósmico-Dinâmico-Escatológica em Teilhard de Chardin”, Perspectiva Teológica 4 (1971) pp. 55-65. Aqui p. 62.
} 


\subsection{A divinização das atividades}

Um hino à ação humana! Como o jesuíta francês foi um pesquisador, um explorador, um homem de ação, compreendemos o quanto ele valorizou o trabalho, o desenvolvimento da ciência, a transformação do mundo, o progresso humano, etc. Para ele, todo esforço em favor do crescimento da noosfera (camada humana refletida da terra) contribui ao acabamento do mundo "in Christo Jesu".

As atividades para Teilhard dizem respeito "àquilo que fazemos, as ações das quais somos sujeitos", guardando a consciência de que toda a força, dinamismo, virtude ou energia motriz de nossos atos é, em última instância, o próprio Amor Divino, a Graça ${ }^{6}$. O mundo do trabalho ganha, pois, um olhar de fé, um olhar inquieto e afoito para tentar compreender o realismo de nossas relações com Deus e das relações de Deus conosco em Cristo. O caráter essencialmente divinisável de nossas atividades é provado por um raciocínio, um silogismo de fé:

No seio do Universo, toda alma é para Deus, em Nosso Senhor.

Mas, por outro lado, toda realidade, mesmo material, em torno de cada um de nós, é para a nossa alma.

Assim, em torno de cada um de nós, toda realidade sensível é, para nossa alma, para Deus em Nosso Senhor?

Esse caminho aparentemente abstrato traz consequências significativas para a existência, sobretudo, quer enfatizar que pela repercussão de nossas obras, mais ou menos distante e direta que têm sobre o mundo espiritual, concorrem para perfazer o Cristo em sua totalidade mística.

A premissa maior (1) expressa o dogma católico fundamental - a vida de Cristo para o cristão é o be-a-bá da fé. Teilhard sinaliza que, não devemos atribuir a essa destinação de nosso ser em Cristo um sentido servil, mas percebermos que entre nós e o Verbo encarnado, existem laços tão rigorosos quanto às poderosas conexões de que o mundo físico e orgânico nos dão exemplos, em todas as ordens ${ }^{8}$.

A premissa menor (2) expressa "um fato natural incontestável, a saber, que nosso ser espiritual se alimenta continuamente das inumeráveis energias do Mundo tangível"9. O sensível passa vitalmente pelas zonas espirituais.

\footnotetext{
${ }^{6}$ TEILHARD, O Meio Divino, nota 21, p. 42.

${ }^{7}$ Ibid., p. 24.

${ }^{8}$ Cf. Ibid., p. 25.

${ }^{9}$ Ibid., p. 26.
} 
Somos assediados por influências cósmicas a serem ordenadas e assimiladas. Por todos os lados, somos inundados por diversas influências do real: alimento para o corpo, repasto para os olhos, harmonia dos sons e plenitude do coração, fenômenos desconhecidos e verdades novas. Todos esses apelos atravessam a nossa consciência, misturando à vida mais íntima de nossa alma para desenvolvê-la ou corrompê-la ${ }^{10}$. Assim sendo, tal premissa explicita que o homem recebendo do meio em que vive, inúmeras energias, é chamado a ordená-las e aplicá-las para o seu crescimento e consequentemente para o acabamento do mundo. É premente nas reflexões de Teilhard a ideia de que no decurso da vida, cada ser humano é chamado a crescer e a se realizar o mais possível ${ }^{11}$, como também a aplicar seus esforços para fazer crescer o reino de Deus. A conclusão se impõe (3). Em torno de cada um de nós, "toda realidade sensível é, para nossa alma, para Deus em Nosso Senhor”. Assim se realiza o anúncio paulino: "Tudo é vosso; mas vós sois de Cristo, e Cristo é de Deus" (1 Cor 3,22-23). O Cristo, por nossa colaboração que ele suscita, consuma-se, atinge sua plenitude, a partir de toda criatura.

O sentido e o valor de nosso trabalho, por mais humilde que seja, contribui para levar a criação à sua consumação em Cristo. Pelo dinamismo sempre em curso da Encarnação, o Divino impregna nossas energias de criaturas, o que possibilita-nos a encontrá-lo e abraçá-lo em nossa própria ação ${ }^{12}$. O nosso trabalho torna-se, pois, caminho de realização pessoal, salvação e de santidade. Quer ele nos seja insípido ou esgotante, quer por ele nos apaixonemos, devemos fazê-lo com todo o empenho, pois sua última grandeza é por assim dizer infinita. Há uma estreita ligação de todos os movimentos deste mundo, no único trabalho da encarnação. Nesta perspectiva, o trabalho por mais elementar que seja, é recebido e utilizado por um Centro divino do universo - o Ponto Ômega ${ }^{13}$.

O trabalho é para todos aqueles que a ele se entregam sem revolta, com fidelidade, um fator de desapego. Primeiro, implica o esforço, a vitória sobre a inércia e o egoísmo. Por mais atraente e espiritual que seja, ele constitui um parto doloroso. Segundo, o desapego consiste em conduzir-nos a um ideal de qualidade espiritual mais elevada. O desapego não diz respeito somente a

\footnotetext{
${ }^{10}$ Cf.,Ibid., pp. 26-27.

${ }^{11}$ Id., Etre plus. Directives extraites des écrits publiés ou inédits du Père, de sa correspondance et de ses notes. Seuil, Paris, 1968. p. 26.

${ }^{12}$ Cf., TEILHARD, O Meio Divino, p. 29.

${ }^{13}$ Ibid., p. 33.
} 
um exercício de ascese purificante, mas, trata-se de uma verdadeira subida do homem, rumo a superar sempre a sua obra e o seu progresso para a perfeição natural: cada realidade alcançada e ultrapassada conduz-nos à descoberta $\mathrm{e}$ à busca de um ideal de qualidade espiritual mais alto. Uma tal visão mística do trabalho conclama, a cristãos e porque não a cada homem, para o dever, o direito e o poder que eles têm de comunicar Deus, mesmo implicitamente, através da face dinâmica de suas atividades. Elas de algum modo nos introduzem no sentido "divino" de nossas passividades.

\subsection{A divinização das passividades}

Reações que dirigem, sustentam ou contrariam nossos esforços! O homem ao mesmo tempo, que pelo próprio avanço de seus poderes, é levado a descobrir objetivos cada vez mais vastos e elevados para a sua ação, pode ser dominado pelo objeto de suas conquistas, ficando preso no que julgou apropriar. Sob o olhar da fé religiosa o cristão sensível aos atrativos da união com Deus pela ação, é capaz de dar um diferencial aos fracassos e contratempos que a vida pouco a pouco lhe impõe, transformando-os, pelo amor, em comunhão. O termo passividade quer dizer o que não é feito por nós é padecido por nós ${ }^{14}$. Teilhard distingue cuidadosamente em nós dois tipos de passividades: passividades de crescimento e passividades de diminuição.

As passividades de crescimento são os sopros da vida que animam, sustentam e fazem crescer nosso ser! "São as forças amigas e favoráveis, que apoiam o nosso esforço e nos dirigem para o sucesso"15; nossa dependência em relação a energias que nos ultrapassam, que recebemos e integramos ao nosso ser a fim de fazê-lo crescer. Seu melhor símbolo é fornecido por Teilhard pela imagem da montanha e do mar, ou mais exatamente pelo que faz o alpinista e o nadador. Tanto para um quanto para o outro, o êxito consiste em irem avançando, tomando um ponto de apoio em tudo o que os rodeia. O que poderia parecer uma barreira onde a ação se consome é, finalmente, o apoio e pode surgir como uma provocação criadora ${ }^{16}$. Essas forças que nos parecem tão naturais (a vontade de ser, o gosto de ser deste ou daquele modo, a oportunidade de realizar nosso bel-prazer), e que, durante nossa vida, fazemos senão seguir o curso ou favorecer o primeiro impulso e os desenvolvimentos se

\footnotetext{
${ }^{14}$ Cf., Ibid., p. 51.

${ }^{15}$ Ibid., p. 52.

${ }^{16}$ Cf. Ibid., p. 81.
} 
originam em e de Deus e estão de sua influência, uma influência que aparece mais distintamente como a energia organizadora do Corpo místico ${ }^{17}$.

As passividades de diminuição são o que nos desconcertam! As forças de diminuição são as verdadeiras passividades e ocorrem de várias maneiras. Elas são "os poderes inimigos, que interferem dolorosamente em nossas tendências, dificultam ou desviam nossa marcha para o ser mais, reduzem nossas capacidades reais ou aparentes de desenvolvimento" ${ }^{18}$. Essas forças que sugam e destroem nossas energias, diminuindo a eficácia aparente e atacando o nosso ser mais íntimo, podem ser se o quisermos, ocasião de uma maior disponibilidade à ação divina.

A morte é como o coroamento das diminuições: ela é o mal físico que resulta das debilidades orgânicas; mas também o mal moral engendrado pelo mau uso da liberdade. Ela é o resumo das diminuições contra as quais temos que lutar sem poder esperar do combate uma vitória pessoal direta e imediata. Aqui nos deparamos com o postulado da fé cristã. Cristo transformou em fator de vivificação aquilo que em si é uma força universal de diminuição e de aniquilamento. Ele venceu a morte quebrando-lhe o aguilhão e pela virtude da Ressurreição, tudo pode se tornar em nossas vidas a bendita influência da vontade de Deus ${ }^{19}$.

O caráter divinisável das nossas diminuições é analisado em dois tempos. Num primeiro, a luta com Deus contra o mal e em seguida, o da nossa aparente derrota e sua transfiguração. O cristão deve lutar sinceramente e com todas as suas forças, em união com o poder criador do mundo, para que todo mal retroceda, para que nada diminua, nem nele nem em torno dele. Agora, após ter feito tudo o que estava ao seu alcance para afastar ou destruir o infortúnio, o fracasso veio... Sua realidade golpeia, mas a resistência interior não pode relaxar. A fé abre um novo campo de possibilidades: na aparente derrota pode surgir a transfiguração.

Semelhante a um artista que sabe aproveitar de um defeito, para tirar do material que esculpe, linhas mais finas, Deus, sem afastar de nós as mortes parciais, transfigura-as, integrando-as num plano melhor. Por três modos Deus pode converter, para os que creem nele, o mal em bem. Primeiro, o fracasso que tivermos sofrido orientará nossas atividades para objetos mais favoráveis, ainda que sempre situados no plano do êxito humano que perseguíamos. Num segundo modo, a perda nos forçará a buscar, num plano menos material, a

\footnotetext{
${ }^{17}$ Ibid., p. 54-55.

${ }^{18}$ TEILHARD, O Meio Divino, p. 52.

${ }^{19}$ Cf. Ibid., p. 57.
} 
satisfação de nossos desejos frustrados ${ }^{20}$. Por último, trata-se dos casos mais difíceis, e, que são precisamente os mais comuns, tais como desaparecimentos prematuros, acidentes estúpidos, etc. É aqui que se manifesta, no campo das nossas diminuições "o modo de ação da Providência, o mais eficaz e o mais santificante" ${ }^{21}$. A morte está encarregada de efetuar, até o fundo de nós mesmos, a abertura desejada.

As diminuições além de justificarem perante nós mesmos a ação de Deus por meio dos males que nos corrompem por dentro e por fora, elas nos colocam em condições de justificar perante os outros homens a legitimidade e o valor humano da resignação. Se o cristão aceita com fé a força inimiga que o abate, sem parar de lutar contra ela, pode tornar-se para ele um princípio estimável de renovação. Se nossos esforços são corajosos, perseverantes, alcançamos Deus, através do mal, mais profundamente do que o mal; e nesse momento nossa "comunhão de resignação" vem a coincidir com nossa fidelidade ao dever humano ${ }^{22}$. A articulação das atividades e das passividades constitui para o jesuíta francês a ascese cristã. Vejamos, pois, esse prolongamento bem como as provocações que o estudo suscita.

\section{Prolongamentos e provocações}

Teilhard de Chardin soube ver nas realidades que atravessam a existência humana o "fio condutor divino que tudo une, tudo ordena e tudo eleva" ${ }^{23}$, delineando, assim, um caminho para a ascese cristã. Tal visão parece-nos contribuir para a vivência de uma experiência religiosa madura no seio do cotidiano, como também abrir perspectivas libertadoras e realizadoras do humano.

\subsection{A ascese cristã}

O empenho e o esforço humanos na busca do progresso pessoal somado à fé estão por detrás da maneira pela qual Teilhard procura amarrar as atividades $e$ as passividades. Ele escreve: "era-me doce, meu Deus, no meio do esforço, sentir que me desenvolvendo eu aumentava o domínio que tendes sobre mim;

\footnotetext{
${ }^{20}$ Ibid., p. 61.

${ }^{21}$ Ibid., p. 61.

${ }^{22}$ Ibid., p. 65.

${ }^{23}$ BOFF, L., Mestre Eckhart. Mística de ser e de não ter. Vozes, Petrópolis, 1983. Aqui p. 15.
} 
era-me doce também, sob a pressão interior da vida, ou entre o jogo favorável dos acontecimentos, abandonar-me à vossa Providência" 24 .

Uma tal atitude nada tem de evasão do mundo, ao contrário, em um primeiro tempo, manifesta a luta ativa e sincera em união com as forças criadoras do mundo. E quando chega o tempo de diminuição, ela é mudança da alegria de agir e no desejo de subir, para o abandono nas mãos do Senhor a fim de que ele transforme a argila humana em fogo divino. Esta dinâmica contempla a ascese cristã, na dupla vertente de atividades/passividades, desenvolvimento/renúncia, apego/desapego. No ritmo da vida cristã, essas duplas harmonizam-se tão bem "como a aspiração e a expiração do ar no funcionamento de nossos pulmões. São os dois tempos da respiração da alma, ou, se prefere, os dois componentes do impulso pelo qual ela toma continuamente pé nas coisas para ultrapassá-las"25.

A ligação das duplas supra mencionadas constitui o mistério da cruz. $\mathrm{O}$ sentido da cruz aponta para a sublimação da lei de toda a vida. "O caminho real da Cruz é bem exatamente o caminho do esforço humano, sobrenaturalmente retificado e prolongado" 26 . As atividades e as passividades são a análise e a verificação das palavras de São Paulo: "pois ninguém de nós vive e ninguém morre para si mesmo, porque se vivemos é para o Senhor que vivemos, e se morremos é para o Senhor que morremos. Portanto, quer vivamos, quer morramos, pertencemos ao Senhor" (Rm 14,7-8). Em outras palavras, por toda a parte, à nossa volta, bastou ultrapassarmos um pouco a zona das aparências sensíveis para vermos transparecer o divino.

A mística teilhardiana é como toda autêntica mística cristã cristocêntrica. Ele sentia Cristo no palpitar da vida e, no chão desta, naquilo que de mais específico e natural constitui a existência humana (trabalhos, alegrias, crescimentos, diminuições, sofrimentos), buscava entrar e estar em comunhão com o Cristo Universal. Por ser uma experiência espiritual que brota do confronto do cristão com o seu cotidiano, parece-nos que a mesma é capaz de oferecer uma maior clareza e conforto para os conflitos humanos, um caminho mesmo que conduz os corações sedentos de transcendência a Deus, cuja face procuram e desejam adorar. Surgem, assim, provocações...

\footnotetext{
${ }^{24}$ TEILHARD, O Meio Divino, p. 62.

${ }^{25}$ Ibid., p. 76.

${ }^{26}$ Ibid., p. 79.
} 
No fundo, a excitante esperança de chegarmos ao mais ser, àquilo que, de fato, dignifica a existência humana.

\subsection{Provocações}

O homem pós-moderno desencantado com a racionalidade tecno-científica e com as pretensões absolutistas da modernidade, busca pelo sagrado. Tem sede de Deus e anseia por Ele. Em parte, podemos constatar esse fato pela explosão de grupos e movimentos religiosos, que estão presentes na sociedade e na Igreja. No horizonte cristão católico, nosso campo de estudo e atuação, é possível constatar que os fiéis estão sedentos por uma vivência espiritual vital e existencial.

A mística da terra, torna-se, pois, inspiradora e significativa para esse contexto globalizado e plurireligioso no qual vivemos. Essa linha, como trabalhada por Teilhard, abarca a dinâmica do cotidiano, mostrando que nossa existência pode tornar-se um encontro no qual Deus se une a nós e nós nos unimos a Ele, no seio mesmo dos esforços realizados e dos obstáculos encontrados. Consideramos que trata-se de uma espiritualidade de encarnação, na qual o dever do trabalho criador e a missão de santificar o mundo se exercem no clima de uma esperança renovada, enriquecida de um fundamento cósmico ${ }^{27}$.

O relacionamento do homem com o Deus vivo no mundo alcança uma dimensão nova e bem concreta. Uma maneira de vivenciar uma espiritualidade purificada das heranças míticas, heterônomas, sacrificais da fé cristã e alicerçada na realidade viva do cristão, com um novo olhar acerca da sua participação na cruz de Jesus ao ritmo das atividades e passividades. Teilhard estava de fato interessado em dialogar com o cristão moderno. Doravante, fundiu antigas tradições ascéticas com a fome moderna de atividades criativas, a busca do divino com a evolução natural e humana, a união mística com a descoberta científica. Ele ensinou a abraçar a presença divina nas coisas ordinárias. "Sem deixar o mundo", mostrou como podemos mergulhar em Deus, para que o nosso mundo seja, verdadeiramente, um ambiente, um meio divino.

Outra provocação que a mística da terra suscita em nós diz respeito a um traço peculiar que a caracteriza - ver. Teilhard adverte-nos que o intento do Meio Divino é o de "ensinar a ver Deus em toda parte: vê-lo no mais secreto, no mais consciente, no mais definitivo do mundo (...) é uma educação do olhar"28. De fato, para Teilhard a vida interior está, essencialmente, aí, na visão. O seu

${ }^{27}$ Cf. MARTINAZZO, Visão Cósmico, p. 56.

${ }^{28}$ TEILHARD, O Meio Divino, p. 14. 
método fenomenológico-científico consiste em ver e fazer ver. O ver trata-se de uma verdadeira ação do pensamento em contínuo crescimento, num aumento de visão, que se dá no aperfeiçoamento progressivo dos órgãos sensíveis (óticos ou não) até a consciência espiritual, comportando uma ampla gama de atuações (enxergar, compreender sinteticamente, ser testemunha de, etc).

Julgamos que a educação do olhar que Teilhard põe em relevo pode também ser compreendida no sentido da escuta atenta da realidade. Este detalhe nos remete à dinâmica que regeu a vida de Jesus - a obediência à vontade do Pai. Ele viveu sua humanidade tendo a obediência como eixo estruturador de toda a sua existência. Para Jesus, obedecer ao Pai significava estar constantemente escutando a vida, escutando o outro. Sua existência humana foi um constante ato de escuta para compreender a vontade do Pai que nem sempre ele percebia com clareza.

Acreditamos e apontamos esse traço do olhar, da escuta atenta da realidade, como um dos pontos que pode caracterizar a experiência mística, quiçá abrir perspectivas libertadoras para o ser humano. O tempo atual incentiva a pressa, a superficialidade, a busca desenfreada pelo ter e vem demonstrando que tudo está instaurado para fazer esquecer o tempo do ser e a escuta refinada que ele reclama. $\mathrm{O}$ desafio da escuta se põe diante nós numa dinâmica reflexiva e de discernimento. Quando a pessoa se coloca com a atitude de ouvinte perante o que a cerca, naturalmente, ela desenvolve a sua capacidade de reflexão. Ao interrogar-se, por exemplo, sobre os acontecimentos, o sentido de sua existência, para onde deseja ir, o resultado de seus esforços, ela está exercendo a sua liberdade e as suas capacidades críticas, ampliando, assim, a visão acerca de si mesma, do mundo que a rodeia, expandindo a consciência. Como nas palavras de Teilhard "a paisagem decifra-se e ilumina ante seus olhos". E numa atitude de fé, a escuta atenta da realidade, a modo da escuta do Nazareno, ajuda-nos no discernimento da vontade de Deus. Recolher o dizer verdadeiro dos acontecimentos que nos circundam, incorporando-o na nossa práxis pode transformar nossa maneira de ser, de viver e de ver as coisas.

\section{Conclusão}

A dupla paixão de Teilhard pelo Absoluto e pela Terra, progressivamente fundida numa única e apaixonada visão do universo convergido para o Ponto Ômega, logrou ser vivida como uma experiência espiritual autêntica. Esta experiência é essencialmente crística. Ele proclamou um mundo perpassado 
pela glória da Páscoa. Cristo, o Verbo encarnado resume, atrai e consuma todas as coisas. A tarefa do cristão, integrado no seu meio, é de fazer convergir todas as energias seletas do mundo, para o Cristo, trabalhando com todo empenho para vencer as forças contrárias à edificação do reino de Deus.

Diante das discussões, muitas vezes estéreis, que o seu pensamento espiritual pode gerar, é um contrasenso reduzir a mística teilhardiana a uma relação puramente natural do homem ao mundo ou como sendo uma espécie de reconciliação gnóstica de Deus e do mundo, da fé e da ciência. Esse misticismo contém uma dupla fidelidade: fidelidade a Deus que se revelou em Jesus Cristo e fidelidade ao mundo tal qual a ciência o descobre. O itinerário desse caminho sinaliza que, em nossas ações nos unimos ao poder criador de Deus, nos tornamos prolongamentos vivos dele. Deus é atingível nas ações e nos obstáculos, pois esses são lugares onde a liberdade humana pode se deixar penetrar pelo poder do amor.

Nessa via mística o cristão se reconhece com a função de divinizar o mundo "in Christo Jesu", a "pôr a mão no arado", a ser plenamente ele próprio, a recolher-se em si mesmo, a tomar os acontecimentos dolorosos como caminho que eleva o espírito e como caminho para o progresso universal. Tal linha nos impele a sermos supremamente realistas e ligados às condições históricas e vitais da existência humana, na busca contínua do crescimento e realização pessoais bem como do aperfeiçoamento coletivo. Acreditamos que essas dinâmicas favorecem um conhecimento mais profundo do ser, em comum união com os outros no mundo e em religação contínua com Deus, verdadeiro meio no qual "vivemos, movemos e existimos".

\section{Referências Bibliográficas}

\section{Principal:}

TEILHARD DE CHARDIN, P., Le milieu divin: essai de vie interieure. Seuil, Paris, 1957. (O Meio Divino. Ensaio de vida interior. Cultrix, São Paulo, 1981).

, Le phénomène humain. Seuil, Paris, 1955. (O Fenómeno Humano. 16

v. Tavares Martins, Porto, 1970. ( Filosofia e Religião).

, A missa sobre o mundo. In , Hino do Universo. Paulus, São Paulo, 1994. pp. 15-39.

, Etre plus: directives extraites des écrits publiés ou inédits du Père, de sa correspondance et de ses notes. Seuil, Paris, 1968. 


\section{Secundária:}

BOFF, L., Mestre Eckhart. Mística de ser e de não ter. Vozes, Petrópolis, 1983. DE LUBAC, H., El pensamiento religioso del Padre Pierre Teilhard de Chardin. Taurus, Madrid, 1967.

DUPLEIX, A., "Pierre Teilhard de Chardin", in G. Reynal (dir.), Dictionnaire des théologiens et de la theologie Chretienne. Bayard, Paris, 1998, pp. 428-429. EUVÉ, F., "Pierre Teilhard de Chardin", in V. Melchiorre (dir.), Enciclopedia Filosófica. v. 11. Bompiani, Milano, 2006, pp. 11331-11335.

LATOURELlE, R., "Teilhard de Chardin”, in R. Fisichella (dir.), Diccionario de Teologia Fundamental. Paulinas, Madrid, 1992, pp. 1401-1411.

MARTELET, G., Activités et passivités dans la vie du chrétien. In:

Teilhard de Chardin. Prophète d'un Christ toujours plus grand. Lessius, Bruxelles, 2005, pp. $79-90$.

MARTINAZZO, F., "Visão Cósmico-Dinâmico-Escatológica em Teilhard de Chardin", Perspectiva Teológica 4 (1971) pp. 55-65.

QUILES, I., Introducción a Teilhard de Chardin. El cosmos, el hombre y Dios. TEA, Buenos Aires, 1975.

RIDEAU, E., O pensamento de Teilhard de Chardin. Duas cidades, Lisboa, 1965. VAZ, H. C. de L., "O itinerário inaciano de Teilhard de Chardin", Revista de espiritualidade Inaciana, 48 (2002) pp. 95-103.

, Universo científico e visão cristã em Teilhard de Chardin. Vozes, Petrópolis, [19-].

, “Teilhard de Chardin e a questão de Deus", Síntese 74 (1996) pp.345-370.

Aparecida Maria de Vasconcelos

Doutoranda em Teologia no PPG da FAJE - BH

Pesquisadora do CNPq - bolsista da FAPEMIG

Artigo Recebido em 16/08/2011

Artigo Aprovado em 21/11/2011 